\title{
Tactics for the surgical handling of neurogenic sacral tumors
}

Táticas para manejo cirúrgico dos tumores neurogênicos sacrais

Johnathan de Sousa Parreira ${ }^{1}$, Adelmo Ferreira ${ }^{2}$, Fabio Teixeira Giovanetti Pontes ${ }^{1}$, Adriano Torres

Antonucci', Natally Marques Santiago', Bruno de Azevedo Oliveira², Luis Henrique Garcia Lopes²,

Pedro Garcia Lopes²

Londrina State University Regional Hospital of Northern Paraná, Londrina PR, Brazil.
${ }^{1}$ Resident in Neurosurgical Services of the University Regional Hospital of Northern Paraná, Londrina PR, Brazil;
${ }^{2}$ Neurosurgeon and Instructor of the University Regional Hospital of Northern Paraná, Londrina PR, Brazil.

Correspondence: Johnathan de Sousa Parreira; Rua Ildefonso dos Santos 100 / Casa 23 / Residencial Gralha Azul 3; 86036 -590 Londrina PR - Brasil; E-mail: jsparreira@yahoo.com.br

Conflict of interest: There is no conflict of interest to declare.

Received 13 December 2011; Accepted 29 December 2011

Neurogenic tumors comprise about $7 \%$ of the sacral tumors. Schwannomas are only $4 \%$ of all the retroperitonal tumors. The diagnosis presents the surgeon with a challenge in deciding which surgical approach: anterior, posterior, or a combination of both ${ }^{1}$.

\section{CASES}

Patient A, 65 years-old, female, with progressive lower back pain over a seven-month period, and paraparesis. The computer tomography (CT) of the spine showed a large, heterogeneous lesion with well-defined borders, diameter measuring $9.2 \mathrm{~cm}$, partial destruction of the sacrum (Fig A), extended to the spinal channel at the S1 level, and towards the pelvis. The patient underwent surgical posterior approach, which is a laminectomy at the L5-S1 level. Excision of the tumor resulted in total freeing of the dural sac and the vertebra. Histological examination confirmed a schwannoma. The follow-up was an improvement in the lumbar sciatic pain and muscle power. Two years of follow-up shows no instability of the sacroiliac joint.

Patient B, 41 years-old, female, suffered lumbar and abdominal pain, with paresthesia in the perineum for five months. The neurological exam showed a bilateral Lasegue sign. Magnetic resonance imaging (MRI) showed a heterogeneous lesion, diameter measuring $4.9 \mathrm{~cm}$, well-delimited, and anterior to the sacrum at the S2-S3 level (Fig B). Transabdominal approach was adopted, with a rupture of the cystic portion occurring at the beginning. The, intracapsular emptying of the tumor were performed. The nerve affected could not be preserved. Histological examination confirmed schwannoma. Postoperative treatment of 46 months revealed no recurrence. Pain had disappeared completely, but paresthesia persists in the perineum.
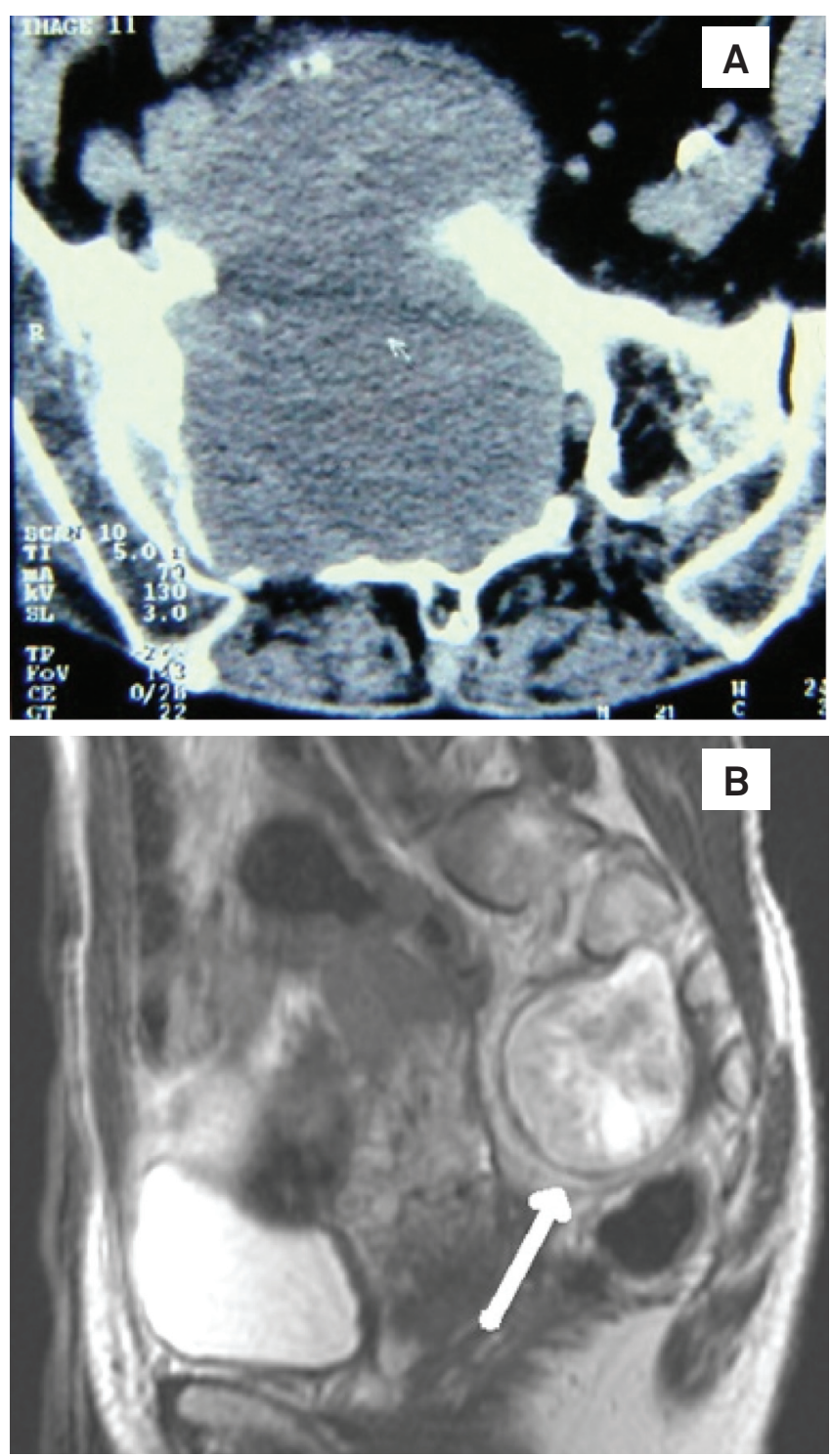

Fig. (A) CT at the S1 level, showing an expansive lesion primarily rightwards, affecting the sacroiliac joint; (B) MRI of the lombossacral column, in the sagittal T2, showing a rounded lesion (arrow) extending towards the pelvic cavity. 


\section{DISCUSSION}

The majority of the sacrum nerve sheath tumors are schwannomas. These tumors usually attain a large size at the diagnosis. Pain (the most common), paresthesia, inflexible bladder, rectal pain, fecal incontinence, or constipation may also occur. Detailed radiological study requires a CT and a MRI. The best treatment is complete surgical excision².

Neurogenic sacral tumors can be classified in four types ${ }^{3}$. Type I tumors growing confines of the sacral canal. Type II tumors grow within the sacral canal and extend out into the sacral foramen (pre-sacral block). Type III tumors grow to form both pre-sacral and anterior blocks. In Type IV, the tumor grows only in the pre-sacral area, without a lesion within the canal itself. In light of this classification, lesions types I,
II, and III that extend outside the sacral canal, below S1 level, can be approached through a simple posterior entry (Patient A). Type IV lesions restricted to the pre-sacral area call for anterior approach (transabdominal). Tumors Types II and III growing outside the sacral canal and extending above the S1 level with a diameter of greater than $10 \mathrm{~cm}$ require a combined anterior-posterior approach ${ }^{1}$.

The main concern in anterior approaches lies in the preservation of the first three sacral nerves, avoiding sphincter dysfunction. The posterior approach may require surgical stabilization ${ }^{4}$. Laparoscopic approach appears to be applicable (pre-sacral tumors), with a few cases already reported in the literature ${ }^{5}$.

Sacral tumors are rare and challenging lesions, calling for a multidisciplinary approach. Careful selection for surgery allows for the successful treatment.

\section{References}

1. Guo W, Tang X, Yang Y, et al. Strategy of surgical treatment of sacral neurogenic tumors. Spine 2009;34:2587-2592.

2. Kim DH, Murovic JA, Tiel RL, et al. A series of 397 peripheral neural sheath tumors: 30-year experience at Louisiana State University Health Sciences Center. J Neurosurg 2005;102:246-55.

3. Guo W, Xu W, Yang Y, et al. A classification system and surgical strategy for sacral tumors. Chin J Spinal Cord 2007;17:605-610.

4. FeldenzerJA, McGauleyJL, McGillicuddy JE. Sacral and pre-sacral tumors: problems in diagnosis and management. Neurosurgery 1989;25:884-891.

5. Konstantinidis K, Theodoropoulos GE, Sambalis G, et al. Laparoscopic resection of presacral schwannomas. Surg Laparosc Endosc Percutan Tech 2005;15:302-304. 